\title{
TERMINAR LA REVOLUCIÓN: \\ EL DEBATE POLÍTICO-CONSTITUCIONAL \\ EN CHILE, 1829-1833
}

\section{Completing the revolution: The political-constitutional debate in Chile, 1829-1833}

\author{
GABRIEL CID \\ Universidad Diego Portales \\ gabriel.cid@udp.cl
}

Cómo citar/Citation

Cid, G. (2017).

Terminar la revolución:

el debate político-constitucional en Chile, 1829-1833.

Revista de Estudios Políticos, 176, 17-45

doi: https://doi.org/10.18042/cepc/rep.176.01

\section{Resumen}

Este artículo examina el proceso de reflexión política posterior a la guerra civil de 1829 en Chile, que buscó encontrar la fórmula constitucional para afianzar institucionalmente los logros de la independencia y poner fin al proceso revolucionario abierto con la separación de la monarquía hispánica. El trabajo explora, desde la perspectiva de la historia intelectual, el proceso de cambio constitucional defendido por los constituyentes de 1830-1833, centrado en algunos problemas políticos fundamentales, cuya resolución había sido esquiva hasta entonces: el problema federal, la delimitación de la ciudadanía política, la reflexión sobre la función de la ley y el reordenamiento del equilibrio de poderes.

\section{Palabras clave}

Revolución; independencia de Chile; constitucionalismo.

\section{Abstract}

The paper examines the political debate after the 1829 Chilean civil war, which sought to find a constitutional formula to institutionally strengthen the 
gains of Independence and finish the revolutionary process begun with the separation from the Spanish monarchy. The paper explores, from the perspective of intellectual history, the process of constitutional change supported by the deputies of $1830-1833$, focusing on some key political problems: the federal issue, the limits of political citizenship, the reflection on the function of law, and the reordering of the balance of powers.

\section{Keywords}

Revolution; Chilean independence; constitutionalism. 


\section{SUMARIO}

I. INTRODUCCIÓN. II. BALANCE CRÍTICO DE UNA ERA REVOLUCIONARIA. III. LA CENTRALIZACIÓN DEL GOBIERNO TERRITORIAL. IV. REDEFINIR LA CIUDADANIIA. V. REPENSAR LA FUNCIÓN CONSTITUCIONAL: PRAGMATISMO Y ORDEN. VI. UN NUEVO EQUILIBRIO: EL PODER EJECUTIVO Y LAS FACULTADES EXTRAORDINARIAS. VII. CONCLUSIONES. BIBLIOGRAFIA.

\section{INTRODUCCIÓN}

Los años siguientes a las declaraciones de independencia en Hispanoamérica se caracterizaron por la dificultad en afianzar un orden político acorde con las expectativas revolucionarias. La inestabilidad institucional, la disgregación territorial del poder, el recrudecimiento de las tensiones interétnicas, las desavenencias ideológicas, la militarización de la política, además del déficit fiscal crónico que legaron las guerras, parecían ensombrecer el horizonte ante la constatación de que esos factores no parecían circunstanciales, sino dificultades de tipo estructural en la consolidación del orden (Safford, 1992).

Parafraseando la distinción arendtiana, las nuevas naciones surgidas tras la disolución de la monarquía se habían liberado, pero no habían consolidado su libertad (Arendt, 2013: 227-228). ¿Cómo terminar la revolución? Tal parecía ser la interrogante crucial afrontada en los años posteriores a las declaraciones de independencia. Un desafío de gran magnitud, pues en casi todo el continente - a excepción de México- la opción monárquica o de un retorno al statu quo ante estaba clausurada. Es más, por la misma dinámica de los procesos independentistas, como sugiere Guerra (1995: 44), los hispanoamericanos habían sido empujados a implementar regímenes de una «modernidad extrema», como la república.

En ese proceso, la transición desde el momento de ruptura a la etapa de creación institucional, la literatura ha coincidido en colocar el caso chileno, en términos de afianzamiento del orden posrevolucionario, como una de las experiencias relativamente más exitosas en el marco hispanoamericano (Kurtz, 2013; Centeno y Ferraro, 2014). Las razones de esta situación, que contribuyeron a cimentar a lo largo del siglo XIX la idea de la «excepcionalidad» a nivel continental, han sido latamente discutidas por la historiografía chilena, pudiendo distinguirse al menos dos corrientes analíticas a la hora de 
interpretar el sentido de la guerra civil de 1829-1830, el conflicto que puso término al período de ensayos constitucionales inaugurado con la declaración de la Independencia.

Por un lado, tempranamente la historiografía de cuño liberal vinculada a la Generación de 1842 interpretó este proceso como una «reacción colonial», como una «reacción anti-revolucionaria, antiliberal» (Bilbao, 1844: 69-72, 79), lectura canonizada posteriormente por Lastarria (1861). Así, la revolución habría sido traicionada en sus principios y la república, desde 1830 en adelante, sería poco más que una "parodia». Desde la otra vereda, la historiografía de signo conservador tendió a ver en el pronto afianzamiento del orden posrevolucionario el resultado casi exclusivo de la obra demiúrgica del "genio» de Diego Portales. Esa lectura, afianzada en obras como las de Walker Martínez, tendría sus momentos de mayor exaltación en el siglo Xx de la mano de trabajos como los de Alberto Edwards, Francisco Antonio Encina y Bernardino Bravo Lira. Si para la historiografía liberal la «reacción colonial» había significado un retroceso en el camino progresista que había abierto la revolución, para la historiografía conservadora esa vuelta al pasado había significado la posibilidad de fundar las bases para el progreso efectivo de la república, al recuperar el sentido de autoridad propio de la colonia para consolidar, de ahí, el «estado en forma».

Lo que tienen en común ambas visiones es que tienden a conceptualizar el republicanismo surgido de aquel momento como una suerte de fachada formal, una lectura persistente incluso en nuestros días (Cristi y Ruiz Tagle, 2006: 14, 93). Estas lecturas predominantes dificultan recuperar una reflexión política mucho más compleja desarrollada en ese lustro clave que se inicia en 1829 y que culmina con la sanción de la Constitución de 1833. Por una parte, por el simplismo de atribuir la consolidación del proyecto republicano a la labor de un «estadista» como Portales, cuyo accionar es más próximo al de un operador político. Y también porque esta visión del problema minimiza el papel de un grupo de juristas y publicistas que articularon la solución constitucional que dotó de un entramado institucional al nuevo régimen, además de suministrarle el soporte ideológico: Agustín Vial Santelices, Vicente Bustillos, Manuel José Gandarillas, Andrés Bello y Mariano Egaña, entre otros.

Por otra parte, estas lecturas resultan incompletas porque obvian lo que era un hecho incuestionable para los contemporáneos, y es que la revolución había triunfado en sus principios. Es decir, esta había suministrado un cúmulo básico de conceptos políticos ineludibles en la reflexión política, que aunque tributarios de diversas tradiciones intelectuales, se habían convertido en un mínimo común denominador: soberanía nacional, pueblo, libertad, igualdad, constitución, república, representación, opinión pública, ciudadanía, nación, 
entre otros. En otras palabras, hacia 1830 era impensable conceptualizar en Chile un régimen que prescindiera de estos elementos constitutivos de la modernidad política, de ahí que, por utilizar un término laxo, la revolución no podía ser sino republicana. Otra cosa es que, a partir de ese mismo corpus conceptual, el nuevo diseño institucional, impregnado de una sensibilidad conservadora, haya diferido en sus énfasis, jerarquías y valores, redefiniendo algunos conceptos y silenciando la posibilidad de interpretaciones políticas alternativas.

En este sentido, el argumento sostenido en estas páginas releva la importancia del proceso de elaboración constitucional impulsado por los juristas y publicistas afines al bando vencedor de la guerra civil de 1829, problema que en general ha sido relegado a un lugar marginal por la historiografía, más centrada en las prácticas represivas del régimen o en personajes controversiales, como Portales. Los rasgos centrales de este proceso, y que examino en detalle en estas páginas, fueron la relectura de la experiencia revolucionaria acumulada que actuó como prisma para dirimir los problemas políticos cruciales irresueltos de la independencia: deslindar los marcos de ejercicio de la ciudadanía, conjurar los riesgos de fragmentación territorial de la soberanía, redefinir la función de la constitución respecto a su relación con conceptos como orden y libertad y, finalmente, reordenar el equilibrio de poderes por medio de un aumento en las prerrogativas del Poder Ejecutivo.

La relevancia de la dimensión constitucional dentro de este problema es evidente. Si bien una serie de prácticas contribuyeron a la gobernabilidad del nuevo régimen - entre las que se cuentan la represión, la cooptación de la Iglesia, la consolidación de la Guardia Cívica como contrapeso al Ejército y la intervención electoral, lo que Collier (2005: 63-75) llama «los soportes principales del sistema»-, el trabajo intelectual que subyace a la deliberación constitucional supuso establecer un entramado normativo para la acción política que dotase de sentido a dichas prácticas. Pensar en ese momento constitucional como el espacio en el que se dirime la finalización del momento revolucionario me parece pertinente al menos por dos razones. En primer término, porque, siguiendo a Ricciardi (2009: 12-20), es en el marco de la institucionalización donde una revolución puede declararse como concluida, en tanto podríamos entender que el fin de una revolución se orienta en los términos de una «saturación jurídica del orden político». Pero, también, porque fue la resolución de ese momento constitucional aquello que singulariza la experiencia chilena en el marco hispanoamericano, en tanto la carta sancionada en 1833 extendió su vigencia — aunque con importantes reformas en las décadas de 1860 y 1870 - durante casi un siglo, hasta la nueva constitución dictada en 1925. En ese sentido, argumento, la experiencia chilena se constituye en 
un espacio privilegiado para analizar un problema político crucial, pero que tiende a ser desplazado en su importancia por la atracción propia de los orígenes: ¿cómo terminar una revolución?

\section{BALANCE CRÍTICO DE UNA ERA REVOLUCIONARIA}

La década de 1830 se caracterizó en Hispanoamérica por la instalación de un discurso de urgencia respecto a la necesidad de finalizar la revolución independentista y culminar con la experimentación constitucional que caracterizó a aquellos años. Si la década de 1820 puede ser conceptualizada como un momento signado por las indefiniciones, como un período de "comienzos imperfectos» y "finales incompletos» (Brown, 2013: 92), la década siguiente sería, en buena parte de Hispanoamérica, un periodo que tendría como objetivo poner fin a los cabos sueltos legados por la revolución, para lo cual el autoritarismo y el centralismo devinieron en las estrategias de resolución de conflictos más invocadas (Bushnell y Macaulay, 1989: 77-83, 111-116).

Puesto que las revoluciones modernas se caracterizan por imaginarse a sí mismas como creadoras de un orden nuevo necesariamente mejor (Arendt, 2013: 42-43), no debe extrañar que el desajuste natural entre lo esperado y lo logrado ocasionara en algunos casos una sensación de desengaño respecto a las promesas revolucionarias. En alguna medida esto fue lo que pasó en Hispanoamérica en 1830, donde el desafío de consolidar el nuevo orden republicano parecía zozobrar entre tantos problemas estructurales. En esa década, Rojas (2009: 192, 319-322) vislumbra una conexión significativa entre republicanismo y conservadurismo, propio de aquel «momento crepuscular que por entonces se vive en el Nuevo Mundo». Una sensación de frustración extendida, perceptible en personajes claves del período como Bolívar, Mier, San Martín y Sucre, quienes en sus escritos muestran el desaliento al constatar la falta de correspondencia entre la república y su soporte social. Tal sería el tópico central, dice Rojas, de aquel «copioso discurso del desencanto» característico desde 1830.

Este discurso es fácilmente perceptible en la prensa chilena. A propósito de la conmemoración de la decisiva batalla de Chacabuco (12 de febrero de 1817), El Mercurio delineó el discurso de la frustración al ver los escasos resultados conseguidos desde esa fecha: «Desde aquel día han transcurrido 14 años sin que en ese largo período se haya conseguido aún el objeto primordial de la separación de la metrópoli: prepararse a obtener el goce sólido de las ventajas que le dan las instituciones libres; hasta ahora no hemos hecho más que desviarnos, nada más hemos sido que las víctimas de las disensiones originadas por la falta de experiencia para conducirnos en nuestro nuevo estado" (El Mercurio, 11-02-1831). 
Las disensiones internas, la inexperiencia política y la falta de costumbres acordes al proyecto republicano parecían explicar los yerros de la revolución, según confidenciaba Juan Egaña: «[...] jamás he dudado que las colonias españolas necesitan como dos siglos de amoldamiento bajo un gobierno que teman y respeten para criar costumbres» (Silva Castro, 1951: 18-19). Según Joaquín Campino, el fracaso de las «republiquetas» hispanoamericanas debía atribuirse al origen de la independencia. En Hispanoamérica la revolución no había sido fruto de un proceso de maduración intelectual, sino que fue un proceso de ruptura inédito que, sobre la marcha de los acontecimientos, devino en la independencia: una revolución que tuvo que explicarse a sí misma en medio del devenir de los sucesos. El proceso de reflexión política, a la zaga siempre de los acontecimientos, se tornaba más complejo por la misma dinámica del «fermento" revolucionario, que había incorporado a la arena de la política moderna a nuevos segmentos de la población, carentes de instrucción cívica. Esto permitía entender el desencanto de aquella generación inmersa en un proceso de transición que parecía inacabable: «He aquí lo que hace mirar el estado actual de todos nuestros países como el síntoma de una fiebre para la cual no hay 'quina', y que es preciso resignarnos por fuerza, porque nada ganamos con desesperarnos. Todo se ha probado: desde la monarquía y el absolutismo militar hasta la más extremada democracia y libertad. La aureola de gloria de Bolívar no ha valido más que el saber y el talento de Rivadavia» (Salas, 1910-1914, III: 260-262).

En la lógica de los constituyentes de la década de 1830, aunque la revolución había triunfado en sus principios le faltaba todavía afianzar institucionalmente sus logros. La explicación de esta tensión residía especialmente en la dinámica político-ideológica de la década de 1820, que se había conformado en un nuevo campo de experiencias a partir del cual debían evaluarse los horizontes de expectativas posibles de la revolución, parafraseando a Koselleck (1993: 333-357). En efecto, la nueva experiencia dejaba de ser cada vez más aquel pasado colonial demonizado por la retórica revolucionaria, frente al cual cualquier cambio podía ser celebrado sin discusión como positivo, y se nutría, de forma creciente, de la propia experiencia revolucionaria. En otras palabras, las expectativas del constitucionalismo de 1820 estaban orientadas inequívocamente hacia el futuro, pues del pasado nada podía ser rescatado. Y si bien el criticismo hacia la colonia no desapareció tras 1830, el nuevo pasado disponible para pensar la política pasó a ser la experiencia de la década previa que era tanto local como continental. En ese sentido, la disponibilidad de una nueva experiencia contribuyó a moderar el contenido de las expectativas republicanas.

Lo que subyacía a este balance crítico de la revolución era la eclosión de una sensibilidad que, a falta de un mejor rótulo, podemos caracterizar como «conservadora». Este conservadurismo, en el caso chileno, no era monárquico 
- por eso no era reaccionario- sino republicano. Lo utilizo asimismo avant la lettre, pues en aquel momento no era un rótulo para perfilar identidades políticas, sino que era una sensibilidad que en poco más de una década tenderá a institucionalizarse por medio de un partido, que les permitirá a sus simpatizantes identificarse a sí mismos como «conservadores». Por eso, más que una etiqueta doctrinaria, es más útil aprehenderlo como una sensibilidad: para ponerlo en términos de Oakeshott (1983), como una «actitud» frente al cambio que expresaría una serie de preferencias: la gradualidad frente a la ruptura, lo real frente a lo posible, lo conveniente a lo perfecto, entre otras.

Estas simpatías, además, pivotan en torno a un conjunto de tendencias claramente distinguibles, que coinciden con lo que Hirschman (1991) delineó como las «retóricas de la reacción». Obviando los equívocos de este último concepto, esta pequeña panoplia de recursos retóricos utilizados por el conservadurismo para defender sus posiciones y denostar a sus enemigos serían las tesis de la perversidad, de la futilidad y del riesgo.

Respecto al primer caso, el discurso progresista de la década de 1820, en su obsesión por la libertad como resultado de su aversión al «despotismo", había terminado consiguiendo un efecto perverso a sus propósitos, en la medida que el abuso de la libertad había devenido en libertinaje y, de ahí, en anarquía. Eso fue la explicación que proponía El Araucano (24-09-1831) para explicar los desvaríos de la revolución chilena: «el mismo horror que concebimos por la tiranía de que acabábamos de salir, nos hicieron adoptar principios muy exagerados: ellos produjeron la anarquía, el desorden y la inestabilidad de nuestras instituciones y gobiernos, y abrieron la puerta a la ambición y las miras particulares de que hemos sido víctimas».

El recurso a la tesis de la futilidad fue particularmente relevante y eficaz en el debate constitucional. En efecto, esta postura se enfocaba en el cuestionamiento a lo que se estimaba había sido un excesivo devaneo intelectual a la hora de establecer diseños constitucionales en la década previa, donde el liberalismo, pecando de un excesivo doctrinarismo, no había podido articular una institucionalidad que hiciera coincidir el "país legal» y el "país real». Era aquel voluntarismo excesivamente optimista en la eficacia de las leyes que, por lo mismo, terminaba siendo fútil al ignorar las estructuras básicas de la sociedad, «creyendo que las aplicaciones de las teorías políticas eran tan fáciles como el estudio de su enmarañado kempis», según un periódico nortino (La Bandera Tricolor, 29-09-1831).

Finalmente, en lo que respecta a la tesis del riesgo, esta también demostró su eficacia retórica para legitimar la labor del nuevo grupo dirigente. Partiendo de la aceptación teórica de los conceptos nodales de la modernidad política, el problema para la sensibilidad conservadora no eran estos principios, sino los riesgos aparejados a su implementación irreflexiva, que en su 
diagnóstico era como se habían llevado a cabo antes de 1829. En otros términos, el problema era que los legisladores no supieron leer el timing para aplicar estos principios, ni habían tenido el tino político para calcular la profundidad en que deberían haberse implementado. Justamente por eso el país se encontraba «al borde del precipicio», como sentenció La Lucerna (11-07-1832). No hace falta añadir que este discurso posicionaba retóricamente a quienes lo formulaban como los patrimonializadores de la gestión adecuada de los principios políticos del republicanismo.

\section{LA CENTRALIZACIÓN DEL GOBIERNO TERRITORIAL}

Uno de los legados más conflictivos del colapso de la monarquía hispánica fue la dispersión territorial de la soberanía. Los esfuerzos por conjurar este proceso y por institucionalizar un régimen que asegurase la convivencia provincial tuvieron su punto álgido en la década de 1820, al calor de los debates entre federalistas y unitarios. El mecanismo consensual ensayado por los constituyentes de 1828, al prescindir de la adjetivación federal o unitaria de la república, fue prontamente impugnado por los constituyentes de 1831, al afirmar en su memoria crítica de dicha carta que esta «no expresa si es unitaria o federal; así es que, abundando en la segunda, no adopta las garantías respectivas que, por otra parte, resiste la constitución natural misma del país; de lo que necesariamente ha resultado la desorganización que nos redujo a la guerra civil» (Letelier, 1887-1908, XXI: 10).

El debate en la prensa sobre este punto intentó en su mayoría apoyar el diagnóstico de la nueva coalición gobernante. El lenguaje político defendido por los medios afines al gobierno insistía en que las instituciones debían adaptarse a las «necesidades», dentro de las cuales la mantención del orden, como precondición para el goce efectivo de la libertad, resultaba ser la prioridad de la nueva coalición dirigente. Para cumplir estos propósitos, y desengañados de la experiencia nacional y continental, El Araucano aclaraba que se había «demostrado tiempo hace que el central es el más convenientes para Chile porque solo bajo esa forma puede asegurarse la tranquilidad de la república entera. Ya sobre esto no hay cuestión; ya todos los partidarios de buena fe de ese ruinoso sistema de dividir la república en trozos para reunirlos después por medio de unas zurciduras tan débiles como perjudiciales», que era lo que proponía el federalismo (El Araucano, 30-04-1831).

Por cierto, algunas voces criticaron la visión del gobierno respecto a la necesidad de restringir las facultades provinciales por considerarlas excesivas y atentatorias contra la gobernabilidad del país. Contra esta postura se planteó un autor que bajo las iniciales T. R. publicó, paradójicamente en El Araucano, 
una defensa de las asambleas provinciales. Según su perspectiva, la cadena de gobierno desde el poder ejecutivo, pasando por los intendentes, gobernadores y miembros de los municipios, estaba bien diseñada en la Constitución de 1828, y si habían existido conflictos entre estos no se debía al modelo, sino a cuestiones personales. Tampoco era válido el argumento según el cual las asambleas provinciales «son unos cuerpos que siempre han mantenido la anarquía en el país». Esta afirmación era errada, aclaraba, pues confundía los planos en los cuales deliberaban los miembros de esta institución, un contexto local que requería conocimientos prácticos y no teóricos, que eran necesarios para la formación de leyes de carácter nacional. Lo que requerían las asambleas provinciales para producir los beneficios esperados era justamente la oportunidad de desplegar las virtudes de esta institución, una oportunidad que por diversas circunstancias no se había presentado. Por eso, concluía, resultaban perjudiciales las opiniones de quienes defendían la eliminación de tales espacios de ejercicio de la autonomía regional, pues estas tenían la función no solo de procurar medidas para la prosperidad de las localidades representadas, sino también de "contener la arbitrariedad de los intendentes y hacer efectiva la Constitución» (El Araucano, 02-07-1831).

Desde la nortina ciudad de La Serena esta visión fue impugnada. Porque para entender la ineficacia de las asambleas provinciales, y la consiguiente necesidad de eliminarlas, había que comprender fenómenos más de fondo que las objeciones analizadas por el comentarista anónimo del Araucano. Para eso era necesario recordar la singularidad política del momento constitucional de 1828, que había sido justamente contemporizar con el federalismo. Por eso la permanencia de las asambleas provinciales resultaba «una verdadera irrisión» en un diseño que no era ni federal ni centralista. De ahí que «las asambleas provinciales son los inválidos de la federación en su estado actual»: ni poseían todas las atribuciones para cumplir adecuadamente sus funciones, como teóricamente - y solo teóricamente- ocurría en el diseño federal, ni tampoco permitía al gobierno central desplegar toda la actividad requerida para mantener el orden público. Así, su ambigüedad constitutiva las volvía prescindibles (La Bandera Tricolor, 17-11-1831).

Perfilado así el escenario, la discusión legislativa buscó puntualizar algunos aspectos que justificaran una decisión - la erradicación de huellas institucionales del pasado federal - que ya estaba tomada. De ahí que los discursos antifederales de ese período insistieran en tópicos de probada eficacia retórica, como la distinción entre la teoría federalista con los resultados concretos a los que había dado lugar en Hispanoamérica y, sobre todo, revitalizar el viejo argumento de cuño culturalista sobre que su éxito en Estados Unidos se debía, más que al modelo, a las costumbres del pueblo norteamericano (El Araucano, 14-04-1832). 
Por eso no debe extrañar que los constituyentes de 1833 desmantelasen sin mayor debate la única institución que podía remitir todavía al imaginario federal, las asambleas provinciales, disgregando sus atribuciones entre la figura del intendente y los cabildos. Andrés Bello justificó este fundamental cambio en su comentario sobre la nueva constitución. Las asambleas provinciales habían sido eliminadas porque su papel en la designación de los intendentes obstaculizaba «aquella dependencia sucesiva y continuada por la cual el Jefe de la República puede hacer efectiva la responsabilidad de todos los agentes de la administración». En el nuevo escenario político abierto tras 1829 no valía la pena conservar aquellas instituciones «que fueron creadas en aquel tiempo como un calmante de los restos de la fiebre federal que en los tiempos anteriores hubo de devoramos», porque habían deambulado entre dos extremos nefastos para el país: "cuando dejaban de ser fantasmas, el de servir de hincapié a las revoluciones». Este punto resultaba clave, pues si lo que requería la república para dar por concluida la revolución era afianzar el orden público, parte de esta estrategia era despolitizar a las comunidades locales, que habían sido faccionalizadas por instituciones como las asambleas provinciales ( $E l$ Araucano, 01-06-1833).

\section{REDEFINIR LA CIUDADANÍA}

La estrategia de despolitización desplegada por el nuevo grupo gobernante se enfocó tanto en constreñir los espacios de participación regional como en redefinir los marcos de participación ciudadana. En su diagnóstico, la dificultad para afianzar las conquistas de la revolución se debía a la incapacidad del liberalismo de la década de 1820 para gestionar uno de los legados inevitables de la independencia: la politización de la sociedad. Porque si bien la movilización política de amplios sectores de la población se estimó clave en el momento de la ruptura con España, en este nuevo momento el goce efectivo de las virtudes atribuidas al republicanismo exigía operar en el sentido inverso: desmovilizando a la sociedad. Lo que había desestabilizado el orden social era la excesiva politización que la breve, pero fundamental, experiencia federalista había legado al país, tanto por aquellas atribuciones brindadas a las asambleas provinciales como por el imaginario de que cualquier autoridad, para ser legítima, debía ser electa directamente por el pueblo, un pueblo que en su materialización política parecía ser excesivamente numeroso.

El trabajo político-intelectual que subyace a este diagnóstico en buena medida ha sido obviado por la historiografía por dos razones imbricadas. En primer término, porque la premisa de que la independencia había sido desde 
su inicio hasta el fin un proceso meramente elitista impedía observar un fenómeno que pronto se mostró como claro: que el supuesto liderazgo incuestionado de las élites del proceso no era tal, ni que el lenguaje político de la época era monocorde. Como lo muestra una copiosa historiografía, las independencias posibilitaron la participación política de las clases populares que, aunque con diversos niveles de sofisticación ideológica o de impacto institucional en su actuación, devinieron en un actor colectivo ineludible en la vida política del período (Guardino, 1996; Sanders, 2004; Di Meglio, 2006; Méndez, 2005). Y en segundo lugar, porque la historiografía ha tendido a asimilar acríticamente el conocido aforismo portaleano, respecto a la «tendencia casi general de la masa al reposo» como aquel elemento que posibilitaba que el orden social chileno descansara sobre "el peso de la noche» (Fariña, 2007, I: 287). Puesto que el orden decía reposar en costumbres naturalmente inclinadas a la moderación, parecía fuera de lugar examinar en el espacio político e intelectual un fenómeno aparentemente sociológico (con excepción de Pinto, 2011).

$\mathrm{Al}$ igual que en el caso referente a las asambleas provinciales, la nueva Constitución de 1833 se planteó críticamente cómo había sido delimitada la ciudadanía en la carta precedente. En efecto, la Constitución de 1828 había establecido en la práctica un sufragio masculino casi universal, al prescindir del requisito de alfabetización y permutar los requisitos censitarios por el servicio en las guardias cívicas. Por eso no debe extrañar la importante movilización provocada por las elecciones presidenciales de 1829 en los grupos populares urbanos, especialmente en los vinculados al mundo artesanal (Wood, 2011: 48-78).

La experiencia de las elecciones de 1829 no hizo sino acentuar aquellas aprensiones iniciales respecto a lo que se consideraba una ciudadanía política demasiado extensa. Así, no debe extrañar que el reglamento para las elecciones del Congreso de Plenipotenciarios fuese un punto de inflexión que prefiguraría un cambio que devendría en permanente respecto a los requisitos para ejercer la ciudadanía activa. En efecto, el reglamento estipulaba la necesidad de alfabetización o, en su defecto, un capital de mil pesos.

Esta renovada importancia del capital quedó más clara al debatirse los requisitos de renta como condición indispensable para poder formar parte del Congreso. Fue El Escrutador el medio que, para defender estos requisitos, perfiló las líneas centrales de un ideario que terminó imponiéndose en el diseño institucional de los años siguientes. El periódico señaló la importancia del capital como factor moderador de las pasiones políticas, justamente por su interés en conservarlo por medio del orden institucional, una moderación que no existía en quienes no arriesgaban nada en las reformas institucionales: «QQué puede esperar la nación de hombres que no tienen ningún interés en la 
conservación del orden por no estar contentos con su suerte [...]?». En una frase decidora, era «el temor a perder lo propio» lo que domesticaba las pasiones y conservaba el orden social, de ahí la necesidad de que los intereses de las clases propietarias fuesen representadas en el Congreso (El Escrutador, 14-11-1830).

El Mercurio agregó un elemento adicional y novedoso en el argumento a favor de la inclusión del requisito censitario. En un dato sintomático que reflejaba la intencionalidad del argumento, el diario porteño celebró el final del proceso de calificación de electores para el Congreso de Plenipotenciarios, cuya cifra había sido de 414 ciudadanos facultados para sufragar. El mismo diario que un año atrás — cuando su línea editorial era afín al liberalismofestejaba la rápida calificación de 1245 personas para votar en el puerto $(E l$ Mercurio, 26-05-1829), ahora defendía la nueva cifra de electores, «el máximum de votantes hábiles que debe producir Valparaíso». La razón de este viraje era la constatación de la peligrosidad de "prodigar con ligereza la acción de votar", que ya dejaba de ser conceptualizado como un derecho para pensarse como una función pública. Por eso había que procurar que «reine la más estricta igualdad entre los votantes hábiles, para que la opinión forme los gobiernos; y no la compra de votos». La igualdad entre los electores autónomos tanto por su racionalidad como por sus posesiones económicas justificaba, especialmente en un escenario de una acentuada estratificación social, la exclusión de aquellos carentes de autonomía y que, por lo mismo, su opinión resultaba mecánicamente la expresión de la voluntad de otro (El Mercurio, 10-11-1830).

La necesidad de repensar los nuevos criterios de la ciudadanía política desde una lógica censitaria fue evidente. Eso quedó claro en la memoria que en octubre de 1831 presentaron Agustín Vial, Francisco Elizalde y Manuel José Gandarillas sobre la necesidad de efectuar la reforma a la Constitución de 1828. En el texto se cuestionó la falta de claridad respecto a la delimitación de los criterios de acceso a la ciudadanía política, especialmente en términos pecuniarios: "La propiedad que se exige es tan vaga que puede reducirse a nada o elevarse arbitrariamente; como que la expresión tener de qué vivir parece que solo excluye a los muertos, porque el vivo se mantiene de algo, y si el qué vivir es relativo a las condiciones y circunstancias, las hay tales que es preciso mucho para vivin (Letelier, 1887-1908, XXI: 10-11).

Aunque la postura fue apoyada desde El Araucano (27-11-1830), al señalar que «el derecho de sufragio solamente debiera concederse a los individuos que sean capaces de apreciarlo en su justo valor», una condición que solo podía asegurarse mediante «una subsistencia decente y cómoda», esta visión distó de ser consensual. "Nuestra constitución», afirmaba un remitido anónimo publicado también en El Araucano (09-07-1831), «no ha 
vinculado el mérito a las riquezas: no es cosa muy rara en nuestro país un ciudadano pobre, pero virtuoso; y tal vez común, hombres ricos que no se harten, y que pueden ceder en los congresos a los estímulos de su propio interés». La réplica a esta objeción no se hizo esperar, afirmando que estas argumentaciones solo sobreinterpretaban algunas excepciones a la regla general que establecía una correlación entre virtud cívica y posición económica (El Araucano, 09-07-1831).

El factor que ayudaría a discernir en la práctica la capacidad del ciudadano no solo remitió al aspecto económico, sino también pivotó sobre consideraciones respecto a la racionalidad del elector, medida por la alfabetización. Si bien la alfabetización como requisito de acceso a la ciudadanía política fue un debate significativo en la década de 1820, la omisión de este requisito por el código de 1828 obligó a recuperar esa discusión e insertarla dentro del proyecto desmovilizador que estamos examinando. Comentando el libro de Charles Lucas Système Penitentiaire, Andrés Bello llegó a la conclusión de que, además de la riqueza, la instrucción era uno de «los mejores garantes de moralidad en los individuos». Por esa razón la ciudanía activa debían circunscribirse a quienes cumplieran con estas dos condiciones: «Las funciones de electores y de jurados, el ejercicio de los derechos civiles, políticos, ¿a quién se confían? ¿A los ignorantes? ¿A los proletarios? No. Propiedad y luces son en todas partes los dos títulos que los hombres presentan a la confianza de la sociedad, y las condiciones fundamentales de toda participación en los negocios públicos» (Fundación La Casa de Bello, 1981-1986, XVIII: 672).

La Constitución de 1833, finalmente, zanjó estas discusiones, al establecer como condiciones de acceso a la ciudadanía 25 años si se era soltero (21 si casado), ser alfabeto (esta disposición solo regiría desde 1840) y cumplir alguno de estos requisitos: una propiedad inmueble cuyo valor sería fijado para cada provincia por una ley especial; el ejercicio de una industria, el goce de algún empleo cuya renta también sería estipulada por la misma ley ${ }^{1}$. Al

1 Constitución de la República de Chile (1833), cap. IV, art. 8.․ De acuerdo a lo consignado por el reglamento de las elecciones de 30 de noviembre de 1833 , para ser elector se debía acreditar, en Santiago, una propiedad inmueble de valor de no menos de 2000 pesos, o un capital del mismo monto; o el ejercicio de un oficio que reportase una renta de a lo menos 200 pesos. En las provincias de Coquimbo, Aconcagua, Colchagua, Talca, Maule y Concepción, los valores serían de una propiedad inmueble de 500 pesos, el capital de 1000 pesos, y la renta de 100 pesos. Finalmente, para las provincias de Valdivia y Chiloé, se exigiría un capital en giro de 500 pesos, una renta de 60 pesos o una propiedad de valor de a lo menos 300 pesos, o cuya extensión fuese de cuatro cuadras de terreno en cultivo. 
comentar el nuevo código constitucional, Andrés Bello se mostró muy complacido por los cambios introducidos en lo relativo a la ciudadanía, en un comentario que puede ser considerado como una síntesis de la visión que desde la coalición conservadora gobernante se levantaría para referirse a los límites de la ciudadanía en el país: «La restricción del derecho de sufragio es una barrera formidable que se ha opuesto a los que en las elecciones hacían de la opinión pública el agente de sus aspiraciones secretas. Únicamente se ha concedido esta preciosa facultad a los que saben estimarla, y que son incapaces de ponerla a la venta» (El Araucano, 25-05-1833).

Los resultados prácticos de este nuevo imaginario político relativo a la ciudadanía son elocuentes. Si en la elección de diputados de 1829 votaron 20287 electores, en 1834, en los primeros comicios bajo la nueva carta lo hicieron 7000, una baja del 66,96\% del electorado (Urzúa Valenzuela, 1992: 84). Este proceso de «jibarización ciudadana» (Pinto y Valdivia, 2009: 219), no obstante, debe ser leído de una forma más compleja que un mero reflujo conservador - aunque mucho de eso tiene-, que ha sido la tesis predominante en la historiografía nacional.

Prescindiendo de algunos matices necesarios, podemos afirmar que en el lustro aquí examinado estamos en presencia de un desplazamiento significativo en la forma de conceptualizar la ciudadanía, en un umbral histórico que se aleja de aquellas formas de imaginar la participación ciudadana en los años anteriores, tales como el interreconocimiento de la comunidad local, típico de la categoría de "vecino", como también del recurso a la virtud cívica característica de la tradición republicana. De forma sintomática, el recurso al «modo de vivir conocido" y a la virtud desaparecieron de la discusión concerniente a la ciudadanía para dar paso a un concepto que se posicionará como el nuevo eje articulador: la «capacidad», es decir la facultad de actuar de forma autónoma tanto racional como económicamente.

El recurso a la capacidad, si bien no es democrático — de hecho, se piensa como contrario a ese principio-, tampoco es simplemente conservador. Es más, desde su formulación original por el grupo de los doctrinarios franceses, la "ciudadanía capacitaria», devino en un aspecto central de la teoría política respecto a la ciudadanía de parte del liberalismo decimonónico (Rosanvallon, 1985: 95-104; Kahan, 2003). Este desplazamiento fundamental en las formas de categorización de la ciudadanía política estaba mutuamente imbricado con otra transformación significativa en el plano del espacio de ejercicio de la ciudadanía: el voto concebido más que como un derecho, como una función. Este cambio, que había sido esbozado tímidamente a fines de la década de 1820, en este nuevo momento adquirió un estatuto hegemónico que, de hecho, también lo sería en general para el liberalismo decimonónico (Ihl, 2004: 38). 


\section{REPENSAR LA FUNCIÓN CONSTITUCIONAL: PRAGMATISMO Y ORDEN}

La crisis de 1829 tuvo como uno de los ejes principales de las discusiones el problema constitucional, cuestión que explica que los bandos contendientes en la guerra civil se autodesignasen como defensores de la constitución. Prescindiendo de la cuestión sobre qué bando era el verdadero defensor de la constitución, lo importante para los propósitos de la argumentación es el rol nuclear que desde la década de 1810, había venido desempeñando la constitución como mecanismo que, paradójicamente, había producido los conflictos políticos pero que, también, teóricamente, permitía clausurarlos. De ahí que el devenir político nacional desde la declaración de independencia estuviese signado por las imputaciones cruzadas que las constituciones del período, fuesen provisorias o solo hayan sido proyectadas, no eran las adecuadas para el contexto chileno. La derogación de las cartas como primera medida tomada por los nuevos grupos en el poder, y la proyección inmediata de otra afín a sus sensibilidades ideológicas, abría así una espiral donde la constitución, imaginada como la encauzadora fundamental del conflicto, siempre podía ser impugnada y redefinida. Por eso no debe extrañar que la crisis constitucional de 1829 haya sido vista por el nuevo grupo dirigente como la oportunidad para cerrar aquella vacatio legis con la promulgación de una nueva carta funcional afín a su sensibilidad conservadora.

En torno al problema de la articulación de una constitución duradera, la mirada de Andrés Bello resulta señera. El gran problema constitucional en Hispanoamérica había sido su deseo de ignorar el legado colonial en la formulación de la nueva legislación republicana, una cuestión que impedía comprender la singularidad de la experiencia revolucionaria continental: lidiar con los legados del despotismo colonial y una legislación hispánica que «mal podían adaptarse al espíritu de nuestras instituciones democráticas». Esa tensión había retardado la implementación del constitucionalismo republicano al provocar un hiato entre la política y la sociedad, porque la discordancia de sus tiempos había dislocado una relación que debería ir a la par. La política marchaba con un vértigo que dejaba a la sociedad siempre a la zaga, dejando al republicanismo hispanoamericano sin un fundamento que dotara de consistencia la reflexión constitucional. En palabras de Bello, esa era la tensión fundacional: «Principios abstractos, que para los más eran denominaciones sin sentido, pugnaban con hábitos y preocupaciones inveteradas, que contaban con auxiliares poderosos en casi todas las profesiones existentes. Constituciones han sucedido a constituciones; y los materiales sobrepuestos no han podido jamás conglutinarse y formar un todo con aquellos que necesariamente debían servirles de basa». Así, la sugerencia era seguir el principio incremental: «[...] 
el mejor remedio que puede aplicarse a los inconvenientes de una constitución que vacila porque no ha tenido tiempo de consolidarse es mantenerla a toda costa, mejorándola progresivamente y sobre todo acomodando a ella las demás partes de nuestra organización política» (El Araucano, 11-11-1830).

La reflexión de Bello se constituyó en un sustrato básico para entender los lineamientos del constitucionalismo conservador de la década de 1830 . Eso se refleja, por ejemplo, en el discurso oficial de Joaquín Prieto. Para lograr una constitución acorde a las nuevas circunstancias, los legisladores optaron por distanciarse de aquella excesiva teorización que se le atribuía a los ensayos constitucionales de la década de 1820 e inclinarse por leyes más pragmáticas que garantizasen ante todo el orden, que devino entonces en un concepto fundamental. Así, en la alocución que dirigió el general Prieto a la Gran Convención, el organismo destinado a reformar la Carta de 1828, les indicó que «el fin de las leyes es la ventura de los hombres y de los pueblos, y no la ostentación de los principios» (El Araucano, 22-10-1832). Esta no fue una idea aislada en Prieto. En su discurso de apertura del Congreso Nacional en junio de 1832, el Presidente aconsejó a los legisladores, señalándoles: «Desnudos de aquel espíritu innovador, que somete a temerarios experimentos la suerte de los pueblos, creeréis sin duda que vuestra misión no es hacer otro pacto social, sino proveer medios que faciliten la ejecución del que existe, y afiancen su permanencia» (Letelier, 1887-1908, XIX: 319).

El cuestionamiento más radical hacia el voluntarismo del primer constitucionalismo chileno vino de Vicente Bustillos. En la memoria leída en la sesión de 6 de noviembre de 1832 en la Gran Convención, Bustillos sostuvo que el problema de las constituciones anteriores había sido la confianza excesiva en el poder performativo de las leyes, lo que había conducido a los legisladores no solo a intentar imponer instituciones ideadas para otras realidades, sino que también los había llevado a establecer una ruptura drástica con el pasado por medio de las leyes, olvidando que estas últimas no pueden imponerse de espaldas a la sociedad. Para el diputado, una de las causas centrales de las desavenencias postindependentistas había sido «el error de confiarlo todo a la escritura, de donde ha nacido la creencia de poder hacer constituciones». Y el problema era precisamente que «la constitución no puede ser escrita, porque siendo existencia y naturaleza ni una ni otra pueden escribirse». Estos dilemas estaban en el centro de la argumentación de Bustillos, para quien era «una obra imposible formar una Constitución a priori». Considerar las costumbres del país como el elemento central que debía orientar la función legislativa debería ser el principio rector de la Gran Convención; de otra forma sería "construir sin terreno donde elevar el edificio". Si los constituyentes aplicaban estos principios solo entonces se superaría la etapa de experimentación 
constitucional que había desestabilizado al país, pues según Bustillos, «lo que hasta aquí hemos hecho, así nosotros como las demás nuevas repúblicas en orden a Constitución, ha sido el papel del mono de la fábula, haciendo fantasmagorías constitucionales sin habernos dedicado antes a encender la lámpara de las costumbres» (La Lucerna, 16-11-1832).

Entre las afirmaciones de Bello, Prieto y Bustillos que hemos examinado, si bien hay un consenso ideológico respecto a su crítica del voluntarismo legislativo, al mismo tiempo reluce una tensión fundamental con la retórica de la nueva coalición gobernante: ¡cómo conciliar la necesidad de una nueva constitución si el objetivo central de este momento era superar la etapa de experimentación de la década de 1820, cuyo rasgo más visible había sido, justamente, la proliferación de textos constitucionales? Bello y Prieto, al menos hasta mediados de 1831, defendían la tesis de reformar la Carta de 1828 — uno de los acuerdos tras la guerra civil — mientras que la dinámica política de ese nuevo momento constituyente había deslizado las posiciones de otro sector dentro de la misma coalición, dentro del que se encontraba Bustillos, hacia la defensa, sin ambages, de hacer una nueva constitución.

A inicios de junio de 1831, Manuel José Gandarillas presentó en el Congreso una moción pidiendo adelantar el período de reforma constitucional, que de acuerdo a la Carta de 1828 debía realizarse en 1836. La Gran Convención, el organismo que hacia octubre de 1831 se encargaría de concretar la moción de Gandarillas, se compondría de un pequeño grupo de miembros afines a la sensibilidad política de la nueva coalición. Su reducido número -36 - permitiría minimizar la ya escasa probabilidad de disenso, siendo una muestra clara del «elitismo político» característico del constitucionalismo conservador, que desconfiaría de los procesos de reflexión colectiva con demasiados actores, en tanto dilatarían el arribo a consensos rápidos y correctos, según argumenta Gargarella (2010: 110).

La puesta en marcha del proceso de reforma constitucional dio paso a una importante discusión periodística respecto a su pertinencia (Leiras, 2004). Quien abrió el debate fue un remitido anónimo firmado con las iniciales T. R. que cuestionaba la reforma proyectada, por ser demasiado radical. Una reforma prematura y demasiado extensa hacia un código ya jurado provocaría una espiral revisionista de leyes que atentaría con la libertad, pues «de ley en ley, se llega a no tener ninguna y a caer por último en el despotismo». Tal había sido el ejemplo revolucionario francés que Chile parecía haber imitado desde la independencia. Por el contrario, el comentarista defendía el principio incremental, como lo sugería la experiencia británica, mejorando ciertos aspectos de la Carta de 1828 (El Araucano, 25-06-1832).

La réplica de Manuel José Gandarillas no se hizo esperar. La Constitución de 1828, en efecto, aunque jurada y con "principios muy buenos", 
resultaba ineficaz para los propósitos políticos de la nueva coalición gobernante, afianzar el orden. Para defender la necesidad de una nueva constitución, el editor del Araucano ponía el acento de su argumento en la clásica dicotomía entre «la teoría de los principios» y «la falta de analogía de ese código con nuestras costumbres", uno de los tópicos más manidos de la retórica conservadora. La inadecuación de la constitución se expresaba en aspectos como una concepción de la ciudadanía demasiado amplia, los escasos requisitos para ejercer la representación y, especialmente, ese pudor antiautoritario que explicaba la no incorporación en su entramado legal de las facultades extraordinarias, un recurso que para Gandarillas resultaba fundamental (El Araucano, 02-07-1831).

La polémica no fue aislada en la prensa. A fines del mismo año, otro remitido anónimo interpelaba a la Gran Convención para detener el proceso de reforma constitucional. Lo que había llevado al país a la crisis de 1829 no había sido la Constitución sino, justamente, la inobservancia de sus prescripciones (El Mercurio, 12-12-1831). Y en este caso, quienes estarían presentando el ejemplo más patente de violación de las normas constitucionales serían, paradójicamente, los encargados de velar por su cumplimiento. Tal era el dilema de una Convención constituyente que obviaba el mandato del código de 1828, que prescribía que su reforma podía efectuarse recién en 1836. Las implicancias de este proceder serían graves en lo mediato, aclaraba el autor: «¿Quién es tan estúpido que no conozca que si el presente Congreso Constitucional ha tenido facultad para adelantar la época de la reforma de nuestra Constitución, el que le suceda no hará lo mismo?» (El Mercurio, 13-12-1831).

El problema del cambio constitucional era que desbarataba toda la legitimidad de un régimen cuyo origen era de por sí cuestionable, la violencia de la guerra civil. Si la nueva coalición había amparado su conducta invocando la defensa de la constitución, con la reforma proyectada, paradójicamente, «se intenta hacer que desaparezca el ídolo a quien dirigíamos nuestros inciensos». Porque aunque algunos medios insistieran en que se trataba de la Carta de 1828 reformada, la nueva constitución proyectada patentizaba uno de los factores que explicaban la errática construcción de un orden político en Hispanoamérica. Este era, afirmaba el publicista, su necesidad de reformarlo todo constantemente por la vía constitucional: «Hoy nos rige una constitución federal, mañana una central, un día es el sistema republicano, otro el aristocrático, y en medio de estas revoluciones todo se destruye y nada se regulariza» (El Araucano, 02-11-1832).

En el fondo, la nueva constitución discutida por la Gran Convención echaba por tierra la retórica legitimante del nuevo régimen, al no fundar su acción en el principio incremental, sino elaborar una carta de principios 
políticos radicalmente distintos del texto a reformar. El nuevo proyecto constitucional, especialmente el elaborado por Mariano Egaña en su Voto particular, era "una mezcla heterogénea de elementos monárquicos y aristocráticos, de ideas viejas y modernas, una copia servil de instituciones extrañas que no tienen la menor analogía con el sistema de la actual Constitución y menos con el país en que se la quiere establecer». En síntesis, se estaba incurriendo en el mismo error que el conservadurismo le reprochaba a los legisladores de la década de 1820: su falta de continuidad entre un texto y otro por la adhesión a institucionalidades foráneas, en su caso, la británica. El comentario era lapidario contra los legisladores de 1831-1833: «Saltar de un sistema a otro enteramente opuesto, dormir hoy republicano para despertar mañana vasallo, y pretender sin tino ni consideración a las circunstancias de un país, trazarle en unos cuantos artículos la marcha que debe seguir, es pugnar con la misma naturaleza, es ladrar a la luna» (El Araucano, 02-11-1832).

Estas críticas no fueron aisladas, pues el discurso en torno a las costumbres nacionales se caracterizaba por su extrema adaptabilidad a los intereses de quien apelaba a él. Por eso la relación entre ley y costumbre tenía una dimensión arbitraria en su vinculación que, así como servía para cuestionar el principismo doctrinal del liberalismo pipiolo, también podía ser esgrimido de forma contraria. Eso fue lo que planteó de forma sarcástica El Hurón (22-051832) al comentar el proyecto constitucional de Mariano Egaña, que a causa de su acentuado autoritarismo respecto a la experiencia política previa, en realidad parecía que su autor se había equivocado de costumbres nacionales: su código, más que a los chilenos, «solo podría convenir a los turcos o a los chinos».

\section{UN NUEVO EQUILIBRIO: EL PODER EJECUTIVO Y LAS FACULTADES EXTRAORDINARIAS}

Las críticas hacia la anglofilia de Egaña revelan un aspecto clave para comprender el nuevo diseño constitucional, y es la confluencia de las figuras de Mariano Egaña y Andrés Bello, admiradoras del modelo británico, en buena medida porque su experiencia biográfica les había permitido presenciar la dinámica de los tumultuosos años 1820 desde Londres (Brahm, 2007: 33-63; Jaksić, 2001: 93-124). En el escenario de inestabilidad institucional, y de reflujos democráticos y autoritarios que caracterizaron a ese momento, solo la monarquía británica parecía haberse librado del marasmo revolucionario y, según Egaña, había sido «el único país que ha quedado a salvo en la inundación general del despotismo que ha cubierto a Europa», y que había sido capaz de preservar sus «instituciones liberales» (González Echeñique, 1984: 73). 
El atractivo del modelo constitucional británico no debería sorprendernos. Si el republicanismo estadounidense era todavía una experiencia reciente, y cuyos éxitos, según la creencia generalizada, parecían deberse más a las virtudes de sus ciudadanos que a sus instituciones, era justamente en esto en lo que radicaba la seducción del caso inglés: era una experiencia perdurable y sus virtudes pivotaban en una adecuada constitución. Dicho atractivo no era reciente en el pensamiento constitucional. Durante el siglo XVIII fue extendida la idea de que la constitución británica era el diseño político más acabado y que impedía la absolutización del poder por un adecuado despliegue de checks and balances (Fioravanti, 2001: 95-100). Como muestra Racine (2010), la influencia británica en las élites hispanoamericanas resulta fundamental, no solo por razones biográficas —entre 1808 y 1830 más de 70 personajes centrales de las independencias vivieron allí- sino, sobre todo, porque la experiencia británica parecía otorgar las herramientas para encauzar el cambio revolucionario: un proceso dirigido desde arriba, sin alterar el orden social y con políticas de cambio gradual, lo que permitiría a las dirigencias hispanoamericanas afianzar institucionalmente los logros de la revolución.

Para sus críticos, la anglofilia de Egaña se expresaba especialmente en el autoritarismo que destilaba su proyecto constitucional, en tanto las prerrogativas del Ejecutivo le aproximaban a las de una monarquía. No obstante, según puntualizaban sus impugnadores, Egaña parecía enfocarse solo en el aumento de las facultades al poder ejecutivo, obviando el resto del entramado constitucional británico, que permitía contrapesar esas atribuciones. Tal fue la crítica planteada por José Miguel Infante. Inglaterra poseía tres pilares que sostenían su libertad: la tolerancia religiosa, la libertad de imprenta y los juicios por jurados, ninguno de los cuales estaba en el proyecto de Egaña. La obsesión del jurista por el orden lo había llevado a adoptar «solo el barniz de aquel decantado edificio». En otras palabras, Egaña había rechazado «lo que tienen de bueno las instituciones políticas de la Gran Bretaña» implementando solamente aquellos elementos "peligrosos a la libertad» (El Valdiviano Federal, 01-06-1832).

Aunque estas críticas se centraban en cómo Mariano Egaña en particular había imaginado un diseño institucional que permitiese ampliar las facultades del ejecutivo, lo cierto es que el jurista solo reproducía una de las formas de pensar lo que a esas alturas se había instalado como un consenso básico dentro del nuevo grupo dirigente. Por lo demás, este reclamo no era reciente. El fracaso del proyecto federalista en 1826 llevó a algunos publicistas y políticos a demandar una mayor concentración de atribuciones en la figura del Ejecutivo, fenómeno del cual eran conscientes los constituyentes de 1828, solo que el recelo liberal respecto al Ejecutivo los hizo mediar entre las posiciones extremas. Esta contemporización del momento de 1828 fue uno de los aspectos en 
los cuales más se ensañó la retórica de la nueva sensibilidad conservadora para defender uno de los puntos centrales de su agenda política: rediseñar el equilibrio de poderes otorgándole una marcada preeminencia al Ejecutivo como mecanismo que permitiría imponer el orden político en un escenario de volatilidad del mismo, un contexto de desestabilización en el cual, cabría agregar, el nuevo grupo dirigente tuvo una altísima cuota de responsabilidad.

Desde fines de 1830 El Araucano (04-12-1830) insistió en la necesidad de reformar la constitución, uno de cuyos aspectos más defectuosos eran las escasas atribuciones otorgadas al poder ejecutivo, lo que imposibilitaba al gobierno afianzar la tranquilidad pública. $\mathrm{Y}$ aunque para algunos comentaristas este balance no era exacto, pues en la Constitución de 1828 el Ejecutivo tendría un poco menos de atribuciones que en la Carta gaditana de 1812, y más que en los Estados Unidos (El Araucano, 02-07-1831), la agenda de ampliación de facultades presidenciales terminó imponiéndose.

Así, no resulta extraño que en el balance crítico de la Constitución de 1828 que presentó en octubre de 1831 la comisión legislativa de la Gran Convención uno de los aspectos más claros que evidenciaban la necesidad de reformarla eran las escasas atribuciones asignadas al Ejecutivo. Para defender este punto la comisión recurrió a la tesis del efecto perverso. Los constituyentes de 1828, guiados por "la exageración de la falsa democracia», habían potenciado al poder legislativo a expensas del ejecutivo, creando así "una magistratura insignificante». Como a causa del prejuicio liberal contra la figura presidencial se habían puesto tantas trabas a su accionar, el liberalismo pipiolo había provocado un efecto perverso: "[...] por huir del despotismo de uno, se cae en el de todos o lo que es lo mismo, en la anarquía» (Letelier, 1887-1908, XXI: 11).

Tal visión fue impugnada por Ladislao Ochoa, en una petición elevada a la Gran Convención. Allí Ochoa solicitaba detener la reforma constitucional porque de continuar esta significaría «el exterminio inevitable de los chilenos». Las razones del sombrío pronóstico estribaban en el aumento excesivo de las atribuciones presidenciales que develaban, en el fondo, una mala resolución de un diagnóstico que era correcto. Si, en efecto, era plausible la tesis según la cual los constituyentes, por huir del despotismo de uno, terminaron creando «un monstruo por cuerpo político, sin cabeza que morigere la acción de los demás miembros», la paradoja era que la Gran Convención estaría deslizándose al extremo opuesto. Su crítica hacia la falta de atribuciones del Ejecutivo los había llevado a "criar otro monstruo, con una cabeza que, en vez de morigerar las acciones y funciones de los demás miembros del cuerpo político, se las absorbe todas». En el fondo, lo que terminaban haciendo los constituyentes era cambiar al titular de la soberanía: este dejaba de ser el "pueblo» y pasaba a ser el presidente (El Correo Mercantil, 18-05-1832). 
$\mathrm{El}$ incremento en las atribuciones al poder ejecutivo en el diseño constitucional de 1833 resulta evidente si se comparan con las de la Carta de 1828. En la nueva constitución el presidente tendría la facultad de nombrar los intendentes provinciales y gobernadores de departamento, además de empleados públicos y oficiales de las fuerzas armadas; el poder de indultar, de iniciativa legal y de veto (con insistencia de dos tercios, pero luego de un año); la posibilidad de reelección inmediata por un período (5 años) y, especialmente, el otorgamiento de facultades extraordinarias, lo que le permitiría decretar el estado de sitio previo acuerdo con el Consejo de Estado. Este último cuerpo vendría en varias instancias a suplir el papel moderador respecto al Ejecutivo que desempeñaba el Congreso en el modelo de 1828, con el cual el presidente debía negociar varias de sus prerrogativas. El Consejo de Estado, además, tenía un carácter meramente consultivo y el presidente tenía directa injerencia en su conformación (Brahm, 2007: 102).

Aunque de claro sesgo autoritario, la Carta de 1833 también había sido objeto de un proceso de negociación, incluso dentro del estrecho margen de disenso existente en la Gran Convención, respecto a otras facultades que otros proyectos paralelos habían sugerido respecto a la figura presidencial: así, por ejemplo, tanto el proyecto que circuló en abril de 1832 como el Voto particular de Egaña permitían la reelección indefinida del mandatario; y mientras el primer proyecto hacía inviolable la figura presidencial, el proyecto de Egaña le confería la posibilidad de disolver el Congreso (Leiras, 2004: 90). En ese escenario, no resultan extraños comentarios como el del Hurón que sentenció que con el diseño constitucional proyectado, «si el Presidente de la República no se convierte en un monarca absoluto, será solamente porque no quiere» ( $E l$ Hurón, 22-05-1832).

El aspecto más evidente y polémico de este giro autoritario fue las facultades extraordinarias otorgadas al presidente, un problema clave en el derrotero del constitucionalismo hispanoamericano de inicios de siglo. Para José Antonio Aguilar (2000: 57-58, 201), tradicionalmente la inestabilidad institucional en la América Latina posrevolucionaria se había atribuido a factores sociales, económicos, culturales e idiosincráticos, pero pocas veces se había reparado en el diseño constitucional escogido por los actores de la época, donde residiría una de sus causalidades ignoradas. El diseño constitucional liberal resultaba inviable en un contexto posrevolucionario al prescindir de las facultades extraordinarias en un escenario de inestabilidad política. El liberalismo, especialmente el tributario de las reflexiones de Constant, excluyó por principio los poderes de emergencia por considerarlos atentatorios contra las libertades individuales, un modelo que en gran parte tomaron los legisladores en América Latina, sin reparar en que ese diseño no contenía mecanismos para preservarse a sí mismo en tiempos de crisis. No deja de resultar 
sorprendente, sin embargo, que Aguilar no examine la excepción más notable de su tesis - que tiende a extrapolar al resto del continente la experiencia mexicana-y que es justamente el caso chileno, el único diseño constitucional surgido en el contexto de las revoluciones hispanoamericanas que sobrevivió a los avatares del siglo XIX.

En cierto sentido, el otorgamiento de las facultades extraordinarias al Ejecutivo en la Carta de 1833 vendría a constitucionalizar una práctica ya operante que, tras la guerra civil, había reflejado una probada eficacia en desmantelar la oposición al nuevo régimen. En efecto, tras la batalla de Lircay el Congreso de Plenipotenciarios otorgó al gobierno facultades extraordinarias para gestionar el escenario de la posguerra civil, atribuciones cuya continuidad fueron defendidas en su eficacia por medios afines al gobierno (El Araucano, 02-07-1831).

La idea de transitar de una situación de facto a una de iure en torno a este problema fue cuestionada por quienes adscribían a un liberalismo tributario de Constant, respecto a que el goce de las libertades individuales no podía suspenderse aun cuando los motivos para hacerlo tuviesen miras paternalistas o buscasen preservar el orden público (Sánchez-Mejía, 1992: 158-160). Así lo hizo el anónimo de iniciales T. R. cuando, tras invocar la autoridad del politólogo lausanés, afirmó que las facultades extraordinarias "pueden ser en gran manera ominosa a la libertad, abriendo la puerta para que a la sombra de la ley se cometan mil arbitrariedades». El amplio espacio de discrecionalidad que abrían estas medidas se tornaba especialmente sensible si se consideraba el contexto de polarización política legado por la guerra civil y la presencia de operadores políticos con escasos escrúpulos dentro de la coalición gobernante. De ahí que exclamara, para oponerse a la inclusión de las facultades extraordinarias en la agenda de reforma constitucional: «Perezca primero el Estado, sepúltese todo en sus ruinas antes de valerse de un medio que pueda ser un instrumento de tales prevaricaciones» (El Araucano, 02-11-1832).

El escenario de polarización política y de fragilidad del orden público crispó la convivencia cívica, porque la gestión de la paz se impuso de forma tan drástica para con los vencidos en la guerra civil que provocó una espiral sediciosa en algunos núcleos de disidencia político-militar. Esta dinámica de círculo vicioso se expresó en un conjunto de conspiraciones contra el régimen de Prieto que, cual profecía autocumplida, terminaba proporcionándole al nuevo gobierno insumos para justificar el recurso a las facultades extraordinarias. Varias conspiraciones dan cuenta de esta situación: la orquestada por José María Labé y Carlos Rodríguez; la liderada por el oficial Domingo Tenorio en Juan Fernández; la de los oficiales Pedro Reyes y Eusebio Ruiz en Colchagua; la de Joaquín Arteaga y Ramón Picarte en Santiago; y, finalmente, la 
denominada «revolución de los puñales» (Sotomayor Valdés, 1980, I: 135$146,265-310)$.

En ese contexto, no debe extrañar la radicalización de las posturas que defendían la necesidad de incorporar en el diseño constitucional las facultades de emergencia y endurecer las sanciones contra los conspiradores. Así, entre las enseñanzas que se podían extraer de la conspiración de Domingo Tenorio, El Araucano (14-01-1832) remarcó «la inutilidad de moderar las penas a los grandes delincuentes con la esperanza de que se enmienden». Mientras que para El Constitucional (18-07-1833) la conspiración liderada por Joaquín Arteaga y Ramón Picarte terminaba otorgándole la razón al gobierno en su idea de aumentar las atribuciones del Ejecutivo y ser inflexibles con la oposición: «La piedad, don del cielo, es una debilidad culpable cuando deja sin castigo a criminales tan descarados y toda transacción con el crimen viene a ser un crimen de parte del que la autoriza».

Andrés Bello, en su comentario a la Constitución de 1833, explicó la necesidad de los poderes de emergencia en el nuevo diseño institucional. En la nueva Carta el presidente había «recibido el vigor necesario para obrar el bien, sometiendo a su autoridad todos los subalternos de que debe servirse para conservar el orden en todo el Estado». Los poderes de emergencia, a diferencia de los diseños constitucionales previos, le otorgaban «al poder fuerza para defenderse contra los ataques de la insubordinación, producida por los excesos de la democracia», aunque el Consejo de Estado, afirmaba inmediatamente Bello en una declaración inevitable dentro de un régimen constitucional, otorgaría a los ciudadanos "recursos con que preservarse del despotismo» ( $E l$ Araucano, 17-05-1833). Para Bello el error del constitucionalismo pipiolo en este punto había sido suponer ingenuamente que la misma ley regularía el disenso en todos los actores del campo político. Los poderes de emergencia serían la muestra palpable de una reconceptualización de lo político como el campo en que opera la imprevisibilidad, de allí que la constitución, en tanto norma que buscaría regular la dinámicas de ese campo, tuviera que incluir las facultades extraordinarias como señal inequívoca de esta variación. Solo con estas medidas se podría afianzar el orden como prerrequisito para la constitución de la libertad efectiva, al permitirle al Ejecutivo disponer de «un dique contra el torrente de las conmociones de partido» y de «apagar el ardor de una inmoderada libertad» (El Araucano, 25-05-1833).

Reflejando la funcionalidad de este viraje político, una de las primeras medidas realizadas bajo la nueva constitución fue, justamente, la solicitud de facultades extraordinarias. A fines de agosto de 1833, el Congreso otorgó poderes de emergencia al Presidente, tras considerar que las recientes conspiraciones hacían necesario "que exista una administración fuerte y vigorosa en estado de contener males tan graves que se repiten con tanta rapidez» (Letelier, 
1887-1908, XXII: 99). Se inauguraba así un clima de paranoia conspirativa del régimen que se extendería a lo largo de toda la década, pero también se iniciaba una dinámica política de insistente invocación al peligro del orden público como precondición para el otorgamiento de facultades extraordinarias del cual, cabría destacar, el nuevo régimen haría uso y abuso por espacio de tres décadas ${ }^{2}$.

Tal había sido la fórmula que el nuevo régimen había encontrado para poner fin al dilema, hasta entonces irresuelto, de poner fin a la revolución. La confluencia en ese momento histórico de un grupo de juristas desencantados con el rumbo liberal de la revolución, adscritos a un constitucionalismo pragmático y en buena medida anglófilo, y de un grupo de operadores políticos de una probada eficacia - dentro del cual descollaba la figura de Portales-, permitieron articular una solución que era tanto teórica como práctica, que incluso con momentos de tensiones dentro de sus formuladores, terminó maniobrando en la tensa arena política de la posguerra civil.

\section{CONCLUSIONES}

En las páginas precedentes he examinado el proceso de reflexión que condujo a los constituyentes de 1830-1833 a articular una solución para un grupo de legados problemáticos resultantes de la disolución de la monarquía hispánica. Este proceso tuvo como sus aspectos centrales una relectura crítica de la experiencia revolucionaria; el esfuerzo por centralizar territorialmente el poder; la redefinición de los marcos de la ciudadanía política y, finalmente, una revisión de la función constitucional, cuyo rasgo más evidente en la discusión fue la preeminencia del orden sobre la libertad. Este viraje se reflejó constitucionalmente en la mayor concentración de poder en la figura del Ejecutivo, siendo uno de los aspectos más sobresalientes la inclusión de los poderes de emergencia como una de sus atribuciones fundamentales. Todo estos cambios políticos, aunque influidos por una sensibilidad conservadora, fueron debatidos a partir de las premisas conceptuales de la modernidad política republicana, lo que le permitió a la nueva Carta de 1833 autodefinir el régimen fundado como "popular representativo".

Con todo, el desenlace de la revolución no dejaba de ser paradójico para el constitucionalismo republicano, que había encontrado con la invocación de los poderes de emergencia la forma de preservarse a sí mismo, aunque anulándose

2 Según muestra Vicuña Mackenna (1863: 137-138), un tercio del período comprendido entre 1833 y 1861 el país vivió bajo estado de excepción constitucional. 
momentáneamente. Estas dos dimensiones, que la suspensión del imperio de la constitución estaba prevista ex ante, y que esta en teoría debía ser solo temporal, eran las que, en los bordes del mínimo aceptable, le permitían al régimen autodefinirse como "popular representativo». Que esta era la forma adecuada (y viable en el tiempo) de poner fin a la revolución de independencia para la nueva coalición gobernante quedó reflejado en las palabras con las que Joaquín Prieto presentó la nueva constitución. En esta los constituyentes habían procedido "despreciando teorías tan alucinadoras como impracticables», suministrando «los medios de asegurar para siempre el orden y tranquilidad pública contra los riesgos de los vaivenes de partidos a que han estado expuestos». En síntesis, con la nueva Carta se podría cumplir con la meta que el país había perseguido por caminos erróneos desde 1818: "poner fin a las revoluciones y disturbios a que daban origen en el desarreglo del sistema político en que nos colocó el triunfo de la independencia» (Valencia Avaria, 1951: 172). Era terminar la revolución.

\section{Bibliografía}

Aguilar, J. (2000). En pos de la quimera. Reflexiones sobre el experimento constitucional atlántico. México: FCE.

Arendt, H. (2013). Sobre la revolución. Madrid: Alianza.

Bilbao, F. (1844). Sociabilidad chilena. El Crepúsculo, 2, 57-90.

Brahm, E. (2007). Mariano Egaña: derecho y política en la fundación de la República Conservadora. Santiago: Centro de Estudios Bicentenario.

Brown, M. (2013). The 1820s in perspective: The Bolivarian decade. En C. Thibaud, G. Entin, A. Gómez y F. Morelli (dirs.). L'Atlantique révolutionnaire. Une perspective Ibéro-Américaine (pp. 91-114). Rennes: Les Perséides.

Bushnell, D. y Macaulay, N. (1989). El nacimiento de los paises latinoamericanos. Madrid: Nerea.

Centeno, M. y Ferraro, A. (eds.) (2014). State and nation making in Latin America and Spain. Republics of the possible. Cambridge: CUP.

Collier, S. (2005). Chile: la construcción de una república 1830-1865. Politica e ideas. Santiago: Ediciones Universidad Católica de Chile.

Cristi, R. y Ruiz Tagle, P. (2006). La república en Chile. Teoría y práctica del constitucionalismo republicano. Santiago: Lom.

Di Meglio, G. (2006). ¡Viva el bajo pueblo! La plebe urbana de Buenos Aires y la politica entre la Revolución de Mayo y el Rosismo (1810-1829). Buenos Aires: Prometeo.

Fariña, C. (2007). Epistolario Diego Portales. Santiago: Ediciones UDP.

Fioravanti, M. (2001). Constitución. Madrid: Trotta.

Fundación la Casa de Bello (1981-1986). Obras completas de Andrés Bello. Caracas: La Casa de Bello, 26 vols.

Gargarella, R. (2010). The Legal foundations of inequality. Constitutionalism in the Americas, 1776-1860. New York: Cambridge University Press. Disponible en: https://doi. org/10.1017/CBO9780511750618. 
González Echeñique, J. (1984). Documentos de la misión de don Mariano Egaña en Londres. Santiago: Ministerio de Relaciones Exteriores de Chile.

Guardino, P. (1996). Peasants, politics, and the formation of Mexico's national State: Guerrero, 1800-1857. Stanford: Stanford University Press.

Guerra, F. X. (1995). Lógicas y ritmos de las revoluciones hispánicas. En F. X. Guerra (ed.). Revoluciones hispánicas: independencias americanas y liberalismo español (pp. 13-46). Madrid: Universidad Complutense.

Hirschman, A. O. (1991). Retóricas de la intransigencia. México: FCE.

Ihl, O. (2004). El voto. Santiago: Lom.

Jaksić, I. (2001). Andrés Bello: la pasión por el orden. Santiago: Editorial Universitaria.

Kahan, A. S. (2003). Liberalism in Nineteenth-Century Europe. The political culture of limited suffrage. New York: Palgrave Macmillan. Disponible en: https://doi. org/10.1057/9781403937643.

Koselleck, R. (1993). Futuro pasado. Para una semántica de los tiempos históricos. Barcelona: Paidós.

Kurtz, M. (2013). Latin America State building in comparative perspective. New York: Cambridge University Press.

Lastarria, J. (1861). Don Diego Portales. Juicio histórico. Santiago: Imprenta del Correo.

Leiras, M. (2004). Ladrando a la luna: periodismo, política y legislación en la elaboración de la Constitución de Chile, 1831-1833. En P. Alonso (comp.). Construcciones impresas. Panfletos, diarios y revistas en la formación de los estados nacionales en América Latina, 1820-1920 (pp. 79-106). Buenos Aires: FCE.

Letelier, V. (1887-1908). Sesiones de los cuerpos legislativos de la República de Chile, 1811 a 1845. Santiago: Imprenta Cervantes, 37 vols.

Méndez, C. (2005). The plebeian republic. The Huanta rebellion and the making of the Peruvian State, 1820-1850. Durham: Duke University Press.

Oakeshott, M. (1983). Qué es ser conservador. Estudios Públicos, 11, 245-270.

Pinto, J. (2011). ¿La tendencia de la masa al reposo? El régimen portaliano enfrenta al mundo plebeyo, 1830-1851. Historia, 44 (2), 401-442.

- y Valdivia, V. (2009). ¿Chilenos todos? La construcción social de la nación (1810-1840). Santiago: Lom.

Racine, K. (2010). «This England and this now»: British cultural and intellectual influence in the Spanish American Independence Era. Hispanic American Historical Review, 90 (3), 423-454. Disponible en: https://doi.org/10.1215/00182168-2010-002.

Ricciardi, M. (2009). ¿Ha terminado la revolución? Historia del concepto y valoración política. Espiral, 15 (44), 9-29.

Rojas, R. (2009). Las repúblicas de aire. Utopía y desencanto en la revolución de Hispanoamérica. México: Taurus.

Rosanvallon, P. (1985). Le moment Guizot. Paris: Gallimard.

Safford, F. (1992). The problem of political order in early republican Spanish America. Journal of Latin American Studies, 24, 83-97. Disponible en: https://doi.org/10.1017/ S0022216X00023798.

Salas, M. (1910-1914). Escritos de don Manuel de Salas y documentos relativos a él y a su familia. Santiago: Imprenta Cervantes/Imprenta Barcelona. 
Sánchez-Mejía, M. (1992). Benjamin Constant y la construcción del liberalismo posrevolucionario. Madrid: Alianza.

Sanders, J. (2004). Contentious republicans: Popular politics, race, and class in nineteenth-century Colombia. Durham: Duke University Press. Disponible en: https://doi. org/10.1215/9780822385745.

Silva Castro, R. (1951). Cartas de don Juan Egaña, 1832-1833. Santiago: Imprenta Universitaria.

Sotomayor Valdés, R. (1980). Historia de Chile bajo el gobierno del general don Joaquin Prieto. Santiago: Academia Chilena de la Historia.

Urzúa Valenzuela, G. (1992). Historia política de Chile y su evolución electoral. Santiago: Editorial Jurídica de Chile.

Valencia Avaria, L. (1951). Anales de la República. Santiago: Andrés Bello.

Vicuña Mackenna, B. (1863). Introducción a la historia de los diez años de la administración Montt. D. Diego Portales. Valparaíso: Imprenta del Mercurio.

Wood, J. (2011). The Society of equality. Popular republicanism and democracy in Santiago de Chile, 1818-1851. Albuquerque: University of New Mexico Press. 